\title{
ERRATUM
}

\section{February 2016 cover caption}

Nat. Chem. Biol. 12 i-iii (2016); published online 19 January 2016; corrected after print 11 February 2016

In the version of this caption initially published, the cover artwork was credited to Erin Dewalt, based on imagery from the author, rather than stating that it was created by Michael B. Battles and the design was by Erin Dewalt. The error has been corrected in the HTML and PDF versions of the caption.

\section{CORRIGENDUM}

\section{Frequency and amplitude control of cortical oscillations by phosphoinositide waves}

Ding Xiong, Shengping Xiao, Su Guo, Qingsong Lin, Fubito Nakatsu \& Min Wu

Nat. Chem. Biol. 12, 158-166 (2016); published online 11 January 2016; corrected online 11 February 2016

In the version of this article initially published online, the name of author Qingsong Lin was misspelled as Qinsong Lin. The error has been corrected for the PDF and HTML versions of this article.

\section{CORRIGENDUM}

\section{SMN2 splice modulators enhance U1-pre-mRNA association and rescue SMA mice}

James Palacino, Susanne E Swalley, Cheng Song, Atwood K Cheung, Lei Shu, Xiaolu Zhang, Mailin Van Hoosear, Youngah Shin, Donovan N Chin, Caroline Gubser Keller, Martin Beibel, Nicole A Renaud, Thomas M Smith, Michael Salcius, Xiaoying Shi, Marc Hild, Rebecca Servais, Monish Jain, Lin Deng, Caroline Bullock, Michael McLellan, Sven Schuierer, Leo Murphy, Marcel J J Blommers, Cecile Blaustein, Frada Berenshteyn, Arnaud Lacoste, Jason R Thomas, Guglielmo Roma, Gregory A Michaud, Brian S Tseng, Jeffery A Porter, Vic E Myer, John A Tallarico, Lawrence G Hamann, Daniel Curtis, Mark C Fishman, William F Dietrich, Natalie A Dales \& Rajeev Sivasankaran

Nat. Chem. Biol. 11, 511-517 (2015); published online 1 June 2015; corrected online 15 July 2015 and 11 February 2016

In the version of this article originally published online, the schematic for the construct in Figure $4 \mathbf{a}$ was incorrect. A corrected figure has been provided in the HTML and PDF versions of the article.

\section{ERRATUM}

\section{ANTIBACTERIALS: Stressing out dormancy}

Grant Miura

Nat. Chem. Biol. 12, 1 (2016); published online 17 December 2015; corrected after print 12 January 2016

In the version of this article initially published, the genus name 'Mycoplasma' was incorrectly used in place of the correct 'Mycobacterium'. The error has been corrected in the HTML and PDF versions of the article. 